\title{
BMJ Open Feasibility and acceptability of advance care planning in elderly Italian and Greek speaking patients as compared to English-speaking patients: an Australian cross-sectional study
}

\author{
Karen Detering, Elizabeth Sutton, Scott Fraser, Kasey Wallis, William Silvester, \\ Daveena Mawren, Kathryn Whiteside
}

To cite: Detering K, Sutton E, Fraser $\mathrm{S}$, et al. Feasibility and acceptability of advance care planning in elderly Italian and Greek speaking patients as compared to Englishspeaking patients: an Australian cross-sectional study. BMJ Open 2015;5: e008800. doi:10.1136/ bmjopen-2015-008800

- Prepublication history for this paper is available online. To view these files please visit the journal online (http://dx.doi.org/10.1136/ bmjopen-2015-008800).

Received 18 May 2015 Revised 17 July 2015 Accepted 31 July 2015

CrossMark

Respecting Patient Choices Program, Austin Health, Heidelberg, Victoria, Australia

Correspondence to Dr Karen Detering; karen. detering@austin.org.au

\section{ABSTRACT}

Objectives: To assess the feasibility and acceptability of facilitated advance care planning (ACP) discussions in elderly Italian and Greek-speaking inpatients compared to English-speaking inpatients.

Design, setting and participants: This crosssectional study with convenience sampling was conducted in Melbourne, Australia, and recruited hospital inpatients with medical decision-making capacity, aged 65 years or above, who spoke Greek (25 patients), Italian (24 patients) or English (63 patients).

Intervention: Facilitated ACP was offered, aiming to assists patients to consider and discuss their goals, values, beliefs and future treatment wishes with their family and doctor; to help them consider how they would like healthcare decisions made in the future if they become unable to do this for themselves; and to complete advance care directives.

Main outcome measures: The completion of ACP discussions, their duration, advance care directive completion and utilisation of interpreters.

Results: Of 112 patients, $109(97 \%)$ had at least one discussion, $63(54 \%)$ completed advance care directives, either nominating a substitute decisionmaker, documenting their wishes or both, and 76 $(68 \%)$ included family in discussions. The median duration of discussions for all patients was slightly more than $1 \mathrm{~h}$, over two visits. There were no differences between the Greek-speaking and the Italianspeaking patients, or between the Non-English speaking and the English-speaking patients in any of these measures. Only 14 non-English speaking patients, $(30 \%)$ utilised interpreters, but when utilised, patients were much more likely $(p<0.005)$ to complete advance care directives.

Conclusions: Facilitated ACP in elderly Italian and Greek-speaking patients is feasible, acceptable and is similar to that for English-speaking patients.

Advance care planning (ACP) is the process of planning for future healthcare,
Strengths and limitations of this study

- Facilitated advance care planning modified to be culturally sensitive to culturally and linguistically diverse populations was provided to Italian and Greek speaking patients.

- Advance care planning feasibility and acceptability, including completion of advance care directives, were measured and compared to a similar group of English speaking patients.

- Given the design of a cross-sectional study with a convenience sample, at a single site together with small numbers of only two language groups of patients, it is difficult to make broad recommendations which would be inclusive of the ethnically diverse population in Australia and internationally.

whereby the person's values, beliefs and preferences are made known, so that these can guide medical decision-making in the future, if that person has lost the capacity to make or communicate their decisions. ${ }^{12}$ This communication between the person, their family, significant others and healthcare providers often results in the identification of a substitute decision-maker and the creation of a written advance care directive. ${ }^{1-3}$ Ideally, the advance care directive allows for the documentation of the person's goals, values and beliefs, as well as any specific future treatment wishes. The advance care directive provides a written record of these, which can then be used to guide future clinical decision-making. Although an advance care directive may be a desirable outcome, the discussions that are central to the ACP process are also valuable in their own right. ${ }^{4}$

In prospective studies and randomised trials, ACP has been shown to significantly 
improve many outcomes for patients and their families. ACP improves the quality of care, including end-of-life care, ${ }^{5}{ }^{6}$ increases the likelihood that a patient will die in their preferred place, ${ }^{67}$ and is associated with increased utilisation of hospice services, and a reduction in hospitalisation and the use of intensive treatments at the end-of-life. ${ }^{468}$ In addition, ACP results in a lower risk of stress, anxiety and depression in the surviving relatives, ${ }^{5}$ and may reduce moral distress among healthcare providers. ${ }^{9}$ Finally there are emerging data showing that ACP reduces the cost of end-of-life care, ${ }^{8}{ }^{10}$ without increasing mortality. ${ }^{4}$

Australia is an ethnically diverse society, with approximately $26 \%$ of the population having been born overseas; $60 \%$ of these originating from non-English speaking countries. ${ }^{11}$ The majority of ACP research and implementation, in Australia and internationally, has involved Caucasian and English-speaking populations. There is increasing recognition that uptake of ACP in culturally and linguistically diverse (CALD) populations is poor. ${ }^{12-15}$ Reasons for this include lack of in-language ACP resources, mistrust of healthcare systems and lack of awareness of ACP. ${ }^{12-16}$ Furthermore, at its core, ACP is grounded in Western bioethics, and places a high value on patient autonomy, informed decision-making and truth telling. These principles, however, may be at odds with the beliefs of many people, families and cultures, both from Western and non-Western backgrounds, who may regard other priorities as paramount. In recognition of this, models of ACP, such as Respecting Patient Choices $^{3}$ have adapted their approaches, and ask people to consider more broadly how they would like decisions made for them, if they become unable to make them for themselves. These models seek to better understand the person's goals, values and beliefs and how these may influence future treatment decisions.

The aim of this study was to evaluate whether a model of ACP that was modified to be culturally sensitive to CALD populations would be feasible and acceptable to such populations.

\section{METHODS}

A cross-sectional study, with a convenience sample, was conducted at the Austin Hospital in Melbourne, Australia and recruited inpatients during April to December 2013.

\section{Study design}

The two commonest languages of non-English speaking Austin Hospital patients are Greek and Italian. Inpatients who listed Greek or Italian as their preferred language, and aged 65 years or above were eligible to participate in the study. As with a previous study, ${ }^{5}$ patients were selected on their expected ability to complete ACP during the current hospital admission. Thus, they needed to be in hospital long enough for ACP to occur, and to have decision-making capacity. Therefore exclusion criteria were: expectation of death or hospital discharge within 2 days, lacking capacity to make medical treatment decisions, or previous completion of formal ACP.

Eligible patients were identified through daily hospital electronic reports of current inpatients, and were approached by a Project ACP Facilitator and offered ACP. An interpreter was available (if needed) to assist with this process. As part of the initial assessment, as is the usual practice at the Austin Hospital when ACP is provided, the trained ACP facilitator made a brief clinical assessment of the patient's decision-making capacity, as judged by their orientation to time, place and person, the ability to understand and discuss their illness, and treatment, and to consider whether they would like to undertake ACP.

The English-speaking group of patients, was offered ACP by the Project ACP Facilitator, during the same time period, and met the same exclusion criteria.

\section{Intervention}

All patients were offered formal ACP from a trained non-medical facilitator using the Respecting Patient Choices model (box 1). This programme involves a coordinated approach to ACP. A trained non-medical facilitator (usually a nurse), working in collaboration with treating doctors, assists the patient and their family to reflect on the patient's goals, values and beliefs, help them to consider how they would like treatment decisions to be made if they became unable to do this for themselves, and to discuss and document any specific preferences. Patients are supported to formally appoint a substitute decision maker, and document their wishes in an advance care directive if they wish. The advance care directive includes sections where specific treatment wishes (cardiopulmonary resuscitation (CPR) and lifeprolonging treatment (LPT)) can be documented, and other sections where the person's goals and values can be recorded.

Italian and Greek speaking patients were provided with in-language ACP brochures. These brochures were developed as part of previous work with these populations. ${ }^{3}$ Patients were also offered hospital interpreters to assist with the ACP conversations. As part of this project, interpreters were provided with specific ACP education, including attendance at the Respecting Patient Choices facilitator workshop (box 1).

\section{Outcome measures}

The main outcome measures were the utilisation (as measures of feasibility and acceptability) of the ACP discussion. These measures included the number of visits by the facilitator to conduct ACP, the total time required to conduct ACP, the type of documents completed, the patient's treatment preferences (if known) and whether an interpreter was used. 


\section{Box 1 Coordinated Advance Care Planning}

1. Advance care planning (ACP) facilitator training includes the following:

A. E-learning, including ACP theory, ethics, law and decision-making capacity assessments. Presented online, with video clips, with online testing.

B. One-day experiential workshop consisting of facilitated discussion and role-play. The primary focus is on "how to have the conversation". During the workshop the participant is expected to complete a full ACP discussion and document the outcome of this discussion in an advance care directive.

2. Components of an ACP discussion

A. Establish how decisions are to be made, if the person becomes unable to speak for themselves (selection of Substitute Decision Maker and determining how they will make decisions).

B. Explore the person's:

- Values, beliefs and what it means to them to "live well"

- Current and future goals and what they would consider to be an acceptable outcome.

- Understanding of their illness, possible treatments and establish whether there are any treatments the person would not wish to have either now or in the future.

C. Summary, documentation and plan for next steps and review.

- Documentation either by completing an advance care directive, or "informally" where the person is clear about their wishes, but did not wish to complete an advance care directive. Where there is "informal" documentation the ACP facilitator documents wishes in a specific area of the medical record.

3. Advance care directives can include one or both of:

A. Legally appointed substitute decision maker.

B. Documentation of wishes.

4. System-wide implementation:

A. Governance, policy and procedures relating to ACP

B. Systematic education and training of healthcare staff including doctors

C. Storage and retrieval of advance care directives

D. Quality improvement

Baseline data collection included age, gender, religion, admission diagnosis and the presence of a 'Resuscitation Plan', a document completed each hospital admission, by doctors indicating treatments to be provided in the event of sudden deterioration.

Continuous data results are reported as mean +/- SD and where appropriate hypothesis testing was performed using students t test. Categorical data were reported as median $+/-$ the IQR. Statistical testing was performed using $\chi^{2}$ with Fisher's exact testing. Data were considered statistically significant at the level of $\mathrm{p} \leq 0.05$.

Given the exploratory nature of this study, in terms of accessing feasibility and acceptability of ACP in Italian and Greek speaking patients, a power calculation was not undertaken.

\section{RESULTS}

\section{Participants}

Of 112 recruited inpatients, 25 spoke Greek, 24 spoke Italian and 63 spoke English. Demographic characteristics are shown in table 1 . There were no significant differences between the Greek and Italian speaking patient groups or between the non-English-speaking patients and the English-speaking groups with respect to patient age, gender or prior completion of a Resuscitation Plan. All Greek and Italian speaking patients identified with a specific religion (Greek: Greek Orthodox 95\%, other $5 \%$, Italian: Catholic 100\%), compared to $75 \%$ of English-speaking patients (Catholic 29\%, Anglican 17\%, other $29 \%$, no religion $25 \%$ ), and this difference was significant $(\mathrm{p}<0.0001)$.

\section{The ACP conversation}

There were no significant differences in either the number of conversations, or the total time the facilitator spent with the patients for the Italian or the Greek-speaking patients, or between these patients groups and English-speaking patients (table 2). In summary, all three groups had a median of two conversations and a median total time spent of just over $1 \mathrm{~h}$ per patient.

\section{The ACP conversation}

There were no differences in the uptake of the ACP conversations between the Italian and Greek speaking patient groups, or between the non-English speaking and the English-speaking patients (table 3). Of 112 patients offered ACP, 109 (97\%) had at least one discussion, 61 (54\%) completed advance care directives (either appointing a substitute decision maker, documenting wishes or doing both) and a further 13 patients (12\%) chose to document their wishes informally (table 3 ). The majority of discussions (68\%) occurred with family members also in attendance.

\section{Use of interpreters}

Interpreter services were offered to all non-English speaking patients who accepted a facilitated ACP discussion (47 patients). Of these:

- Two patients (1 Greek, 1 Italian) subsequently declined ACP.

- Fourteen (30\%) (6 Greek, 8 Italian) accepted the use of an interpreter.

- Twenty seven (57\%) (15 Greek, 12 Italian) elected to use family members to interpret.

- Four (9\%) (2 Greek, 2 Italian) chose to complete ACP in English.

There was no difference in the rate of use of interpreters between the Italian and Greek speaking groups. 
Table 1 Patient demographics

\begin{tabular}{|c|c|c|c|c|c|c|}
\hline & \multicolumn{4}{|c|}{$\begin{array}{l}\text { Non-English speaking background (NESB) } \\
\text { patients }\end{array}$} & \multirow[b]{2}{*}{$\begin{array}{l}\text { English-speaking } \\
\text { background (ESB) }\end{array}$} & \multirow[b]{2}{*}{$\begin{array}{l}p \text { Value } \\
\text { NESB/ESE }\end{array}$} \\
\hline & Greek & Italian & $\begin{array}{l}\text { p Value- } \\
\text { Greek/Italian }\end{array}$ & Total & & \\
\hline Patient cohort size $(n)$ & 25 & 24 & & 49 & 63 & \\
\hline Age at referral (median, IQR) & $79(8)$ & $85(11)$ & 0.21 & $82(11)$ & $81(13)$ & 0.89 \\
\hline Sex: male $\mathrm{n}(\%)$ & $11(44)$ & $8(33)$ & 0.56 & $19(39)$ & $25(40)$ & 1.00 \\
\hline Identify with a religion & $25(100)$ & $24(100)$ & 1.00 & $49(100)$ & $47(75 \%)$ & 0.0001 \\
\hline \multicolumn{7}{|l|}{ Main diagnostic group n (\%) } \\
\hline Cardiopulmonary & $6(24)$ & $13(54)$ & 0.04 & $19(39)$ & $22(35)$ & 0.70 \\
\hline Oncological & $6(24)$ & $6(25)$ & 1.00 & $12(24)$ & $11(17)$ & 0.48 \\
\hline Neurological & $2(8)$ & $2(8)$ & 1.00 & $4(8)$ & $8(13)$ & 0.56 \\
\hline Other disease & $11(44)$ & $3(13)$ & 0.03 & $14(29)$ & $22(35)$ & 0.54 \\
\hline $\begin{array}{l}\text { Resuscitation plan completed prior } \\
\text { to ACP } \mathrm{n}(\%)\end{array}$ & $12(48)$ & $14(58)$ & 0.571 & $26(53)$ & $31(49)$ & 0.71 \\
\hline
\end{tabular}

Where an interpreter was utilised, both Greek and Italian patients were more likely to complete advance care directives $(p<0.005)$ than where conversations occurred without interpreters present (table 4).

\section{Specific wishes documented in advance care directives}

Of the 23 patients who completed advance care directives, (table 5) all documented wishes regarding CPR and $19(83 \%)$ documented wishes regarding other LPT. Of these:

- No patients requested either treatment irrespective of the likely outcome.

- Five patients wanted CPR, and seven wanted LPT only if a predefined acceptable outcome was likely.

- Thirteen patients did not want CPR at all, and six did not want LPT at all.

- Five patients wanted to delegate the CPR decision, and six wanted to delegate LPT decisions to someone else.

\section{DISCUSSION}

This study demonstrates that facilitated ACP is both feasible, and acceptable to a cohort of elderly Italian and Greek-speaking hospital inpatients, and is similar to that of English-speaking patients. Specifically this study demonstrates similar rates of ACP uptake, advance care directive completion, and time required for the conversations. Utilising ACP-trained interpreters improves advance care directive completion rates in the non-English speaking patients.

This study shows similar findings to our previous research, including a randomised controlled trial of 309 English-speaking elderly inpatients, ${ }^{5}$ and a series of 1463 consecutive and predominantly English-speaking hospital inpatients seen by the ACP service during 20102011. ${ }^{17}$ The rate of completion of advance care directives in this study (58\%) is comparable to the 2010 study (56\%), but higher than the series (32\%). In this study, however, patients were more likely to appoint a decisionmaker, without documentation of wishes $(60 \%)$, as compared to only approximately one-third of patients doing so in the other two studies. Only $3 \%$ of patients in both this and the 2010 study declined the offer of ACP, dispelling the myth that patients, including non-English speaking patients, reject ACP.

The findings in this study are contrary to other research showing that people from Western and non-Western, non-English speaking backgrounds are not interested in ACP or completing advance care directives. ${ }^{12-15}$ ACP is a complex intervention with multiple components that, like advance care directives, varies considerably ${ }^{4}{ }^{6}$ throughout the world. We believe there are some key factors included in our ACP intervention (box 1) that have contributed to the success of ACP in this study.

Table 2 Time taken by advance care planning facilitator

\begin{tabular}{|c|c|c|c|c|c|c|}
\hline & \multicolumn{4}{|c|}{ Non-English speaking background (NESB) } & \multirow{2}{*}{$\begin{array}{l}\text { English-speaking } \\
\text { background (ESB) } \\
(n=62)^{\star}\end{array}$} & \multirow[b]{2}{*}{$\begin{array}{l}\text { p Value } \\
\text { (NESB/ESB) }\end{array}$} \\
\hline & $\begin{array}{l}\text { Greek } \\
(n=24)^{\star}\end{array}$ & $\begin{array}{l}\text { Italian } \\
(n=23)^{\star}\end{array}$ & $\begin{array}{l}\text { p Value } \\
\text { Greek/Italian }\end{array}$ & $\begin{array}{l}\text { Total } \\
(n=47)^{\star}\end{array}$ & & \\
\hline Number of visits: median (IQR) & $2.0(1.00)$ & $2.0(2.00)$ & 0.51 & $2.0(1.0)$ & $2.0(1.25)$ & 0.26 \\
\hline $\begin{array}{l}\text { Total time (minutes)median } \\
\text { (IQR) }\end{array}$ & $75(38)$ & $75(90)$ & 0.64 & $75(75)$ & $75(78)$ & 0.29 \\
\hline
\end{tabular}


Table 3 Utility of advance care planning discussion

\begin{tabular}{|c|c|c|c|c|c|c|}
\hline & \multicolumn{4}{|c|}{ Non-English speaking background (NESB) } & \multirow{2}{*}{$\begin{array}{l}\text { English-speaking } \\
\text { background (ESB) } \\
(n=63)\end{array}$} & \multirow[b]{2}{*}{$\begin{array}{l}\text { p Value- } \\
\text { NESB/ESB }\end{array}$} \\
\hline & $\begin{array}{l}\text { Greek } \\
(n=25)\end{array}$ & $\begin{array}{l}\text { Italian } \\
(n=24)\end{array}$ & $\begin{array}{l}\text { p Value-- } \\
\text { Greek/ltalian }\end{array}$ & $\begin{array}{l}\text { Total } \\
(n=49)\end{array}$ & & \\
\hline Accepted discussion $\mathrm{n}(\%)$ & $24(96)$ & $23(96)$ & 1.00 & $47(96)$ & $62(98)$ & 0.58 \\
\hline $\begin{array}{l}\text { Advance care directive } \\
\text { completed } n(\%)\end{array}$ & $15(63)$ & $13(57)$ & 0.78 & $28(60)$ & $35(56)$ & 0.85 \\
\hline \multicolumn{7}{|l|}{ Advance care directive } \\
\hline $\begin{array}{l}\text { Substitute decision maker } \\
\text { only }\end{array}$ & $10(66)$ & $9(69)$ & 1.00 & $19(73)$ & $21(60)$ & 0.43 \\
\hline Documented wishes only & 0 & 0 & - & 0 & $1(3)$ & - \\
\hline Decision-maker and wishes & $5(33)$ & $4(36)$ & 1.00 & $9(35)$ & $13(37)$ & 1.00 \\
\hline Informal documentation & $3(13)$ & $4(17)$ & 0.69 & 7 (15) & $6(10)$ & 0.55 \\
\hline Family involved in discussion & $17(68)$ & $16(67)$ & 1.00 & $33(67)$ & $43(68)$ & 1.00 \\
\hline
\end{tabular}

First with respect to substitute decision-making, our ACP programme considers this more broadly and asks the question "How would you like decisions made, if you become unable to make them yourself?" In this way the person is able to choose who would make decisions and how they would like this decision-maker to act (make decisions based on the person's expressed wishes, make decisions based on their own views, group consensus, overall benefit to the family etc.) In this way both notions of individualism (autonomy, informed consent, and truth telling), and familism/collectivism (familysovereignty, familial roles and obligations) ${ }^{13-16}$ can be supported. This is crucial because, although many people value autonomy and find it empowering, others including people from Western and non-Western cultures, find it isolating and believe that communities and families, not just individuals alone, are affected by lifethreatening illnesses and the decision-making associated with it. ${ }^{14}$ Previous Australian research has shown that for elderly Italian people, many prefer family-based decisions, ${ }^{16}$ and that Greek people find "autonomy and informed consent concepts dangerous and disruptive."13

Second, like others, ${ }^{18-20}$ our ACP conversations include enquiry into the person's goals, values and beliefs and how these may influence future medical treatment decisions. The focus is also on the person's views regarding what would be an unacceptable outcome rather than holding detailed discussions about specific interventions about which they may not have a full understanding or have experienced. We do, however, include the option of discussion and documentation regarding preferences for CPR and LPT. Although in this study only 23 patients (9 from non-English speaking background) completed advance care directives outlining their wishes, the majority completed these treatment sections, with most requesting treatment limitation, and some $(5 / 23$ for CPR, 6/23 for LPT) wishing to delegate decision-making to someone else. This is in distinct contrast to literature suggesting that people from CALD background choose aggressive treatments. ${ }^{13} 14$

The advance care directive includes sections where the person's goals and values can be documented in order to facilitate future communication of these. While the discussions that are central to the ACP process are valuable in their own right, ${ }^{4}$ documenting the outcome of the discussions in a way that is helpful to future decision-making is important. This is especially important in modern medical practice, where a patient's care is often managed by multiple health professionals, in a range of locations.

Third, we utilise trained non-medical facilitators to make ACP more available to all patients, including

Table 4 Utility of ACP conversations with and without interpreters

\begin{tabular}{|c|c|c|c|c|c|c|c|}
\hline & \multicolumn{3}{|c|}{ With interpreter (I) } & \multicolumn{3}{|c|}{ Without interpreter (WI) } & \multirow[b]{2}{*}{$\begin{array}{l}\text { p Value } \\
\text { I/WI }\end{array}$} \\
\hline & $\begin{array}{l}\text { Greek } \\
(n=6)\end{array}$ & $\begin{array}{l}\text { Italian } \\
(n=8)\end{array}$ & $\begin{array}{l}\text { Total } \\
(n=14)\end{array}$ & $\begin{array}{l}\text { Greek } \\
(n=17)\end{array}$ & $\begin{array}{l}\text { Italian } \\
(n=14)\end{array}$ & $\begin{array}{l}\text { Total } \\
(n=31)\end{array}$ & \\
\hline ACD completed n (\%) & $6(100)$ & $6(75)$ & $12(86)$ & $9(53)$ & $7(50)$ & $16(52)$ & $<0.005$ \\
\hline \multicolumn{8}{|l|}{$A C D$} \\
\hline Substitute decision-maker only & 3 & 3 & 6 & 7 & 6 & 13 & 1.00 \\
\hline Documented wishes only & 0 & 0 & 0 & 0 & 0 & 0 & - \\
\hline $\begin{array}{l}\text { Both decision-maker and } \\
\text { documented wishes }\end{array}$ & 3 & 3 & 6 & 2 & 1 & 3 & 0.02 \\
\hline Informal documentation & 0 & 1 & 1 & 3 & 3 & 6 & 0.41 \\
\hline No decisions following ACP & 0 & 1 & 1 & 5 & 4 & 9 & 0.14 \\
\hline
\end{tabular}


Table 5 Treatment wishes documented in advance care directives

\begin{tabular}{|c|c|c|c|c|c|}
\hline & \multicolumn{3}{|c|}{ Non-English speaking } & \multirow[b]{2}{*}{ English speaking } & \multirow[b]{2}{*}{ Tota } \\
\hline & Greek & Italian & Total & & \\
\hline Number with section completed & 5 & 4 & 9 & 14 & 23 \\
\hline \multicolumn{6}{|l|}{ Cardiopulmonary resuscitation } \\
\hline Yes & 0 & 0 & 0 & 0 & 0 \\
\hline Yes*_outcome based & 1 & 0 & 1 & 4 & 5 \\
\hline No & 2 & 3 & 5 & 8 & 13 \\
\hline Delegate $†$ & 2 & 1 & 3 & 2 & 5 \\
\hline Not completed & 0 & 0 & 0 & 0 & 0 \\
\hline \multicolumn{6}{|l|}{ Life-prolonging treatment } \\
\hline Yes & 0 & 0 & 0 & 0 & 0 \\
\hline Yes*-outcome based & 2 & 1 & 3 & 4 & 7 \\
\hline No & 1 & 1 & 2 & 4 & 6 \\
\hline Delegate† & 1 & 1 & 2 & 4 & 6 \\
\hline Not completed & 1 & 1 & 2 & 2 & 4 \\
\hline
\end{tabular}

CALD patients. By also providing professional interpreters who have received specific ACP training we believe language and cultural barriers are lessened. This is similar to the experience of others utilising trained interpreters for ACP discussions in Spanish and Russian speaking patients. ${ }^{21}$ In this current study advance care directives were more likely to be completed when an interpreter was present, and we consider that spending time training the interpreters was an important part of this project, even though less than one-third of patients used the interpreter for their ACP conversations.

Another important factor for effective ACP discussions is the inclusion of family in the discussions. If present, family are able to be actively involved in the process, be aware of and support decisions, understand their future roles, and as a result feel less burdened by future decision-making. ${ }^{5}$ When family are present, advance care directives are more likely to be completed. ${ }^{5}$ Furthermore, having family present for ACP discussions facilitates better understanding of patient goals and preferences and, thereby, families are then more likely to make decisions consistent with the person's wishes. ${ }^{22}$

\section{Limitations of this study}

This study, was conducted at a single site, was not a randomised trial, and included small numbers of two CALD populations. Furthermore, both CALD patient populations studied are from Western backgrounds. It is, therefore, difficult to make broad recommendations which would be inclusive of the ethnically diverse population in Australia and internationally. Given the methods and sample size of the study, it is also not possible to explore in any detail which components of the ACP process are crucial to rates of ACP uptake and completion seen in this study. Furthermore, this study did not look at whether ACP affected future decision-making and end-of-life care. Lastly, although this study found no difference in the duration of facilitated ACP between the groups, there are many factors that can impact on, and therefore confound, this measure, and these were not explored in this study.

\section{CONCLUSION}

This small study demonstrates that ACP in hospital inpatients of two of the commonest CALD groups in Australia is feasible and acceptable with results being similar to those of English speaking patients. Further work is required, with a larger sample size, in more diverse ethnic groups, including non-Western populations to help determine which components of the modified ACP model were most important, and whether this model is feasible and acceptable with other ethnic populations.

Contributors KD was involved in the conception, design, interpretation and drafting of manuscript; ES was involved in the conception, design, interpretation and revision of manuscript; SF was involved in the analysis and interpretation of data, and review of manuscript; KWa was involved in the design, data acquisition, and review of manuscript, WS was involved in the interpretation of data and review of manuscript, DM data analysis, and review of manuscript; KWh was involved in the data acquisition and review of manuscript. All authors gave final approval of the version to be published. KD is the guarantor.

Funding This research was carried out using staff employed in the Respecting Patient Choices programme, which receives funding from the Australian Commonwealth and Victorian State Governments. No external funding was utilised.

Competing interests None declared.

Ethics approval Ethics approval was obtained from Austin Health's Human Research Ethics Committee.

Provenance and peer review Not commissioned; externally peer reviewed.

Data sharing statement No additional data are available.

Open Access This is an Open Access article distributed in accordance with the Creative Commons Attribution Non Commercial (CC BY-NC 4.0) license, which permits others to distribute, remix, adapt, build upon this work non- 
commercially, and license their derivative works on different terms, provided the original work is properly cited and the use is non-commercial. See: http:// creativecommons.org/licenses/by-nc/4.0/

\section{REFERENCES}

1. The Clinical, Technical and Ethical Principal Committee of the Australian Health Ministers' Advisory Council. A national framework for advance care directives (cited May 2015). http://www.health.wa. gov.au/advancecareplanning/docs/AdvanceCareDirectives2011.pdf

2. Victorian Department of Health. Advance care planning: have the conversation. A strategy for Victorian health services 2014-2018 (cited May 2015). http://docs.health.vic.gov.au/docs/doc/ C1BEDB926ED9A6E7CA257C9A0005231A/\$FILE/

Advancecareplanning-strategy2014-18.pdf

3. Advance Care Planning Australia. (cited May 2015). http:// advancecareplanning.org.au/advance-care-planning

4. Houben $\mathrm{CH}$, Spruit MA, Groenen MT, et al. Efficacy of advance care planning: a systematic review and meta-analysis. J Am Med Dir Assoc 2014;15:477-89.

5. Detering KM, Hancock AD, Reade MC. The impact of advance care planning on end of life care in elderly patients: randomised controlled trial. BMJ 2010;340:c1345.

6. Brinkman-Stoppelenburg A, Rietjens JA, van der Heide A. The effects of advance care planning on end-of-life care: a systematic review. Palliat Med. 2014;28:1000-25.

7. Molloy DW, Russo R, Pedlar D, et al. Implementation of advance directives among community-dwelling veterans. Gerontologist 2000;40:213-17.

8. Teno JM, Gruneir A, Schwartz Z, et al. Association between advance directives and quality of end-of-life care: a national study. J Am Geriatr Soc 2007;55:189-94.

9. Elpern EH, Covert B, Kleinpell R. Moral distress of staff nurses in a medical intensive care unit. Am J Crit Care 2005;14:523-30.

10. Zhang B, Wright AA, Huskamp HA, et al. Health care costs in the last week of life: associations with end-of-life conversations. Arch Intern Med 2009;169:480-8.
11. DIAC. The People of Victoria: Statistics from the 2011 Census. http://www.multicultural.vic.gov.au/images/stories/documents/2014/ RAC_documents/a2-section1-australianoverview-pp1to55.pdf (cited 25 April 2015)

12. Kwak J, Haley WE. Current research findings on end-of-life decision making among racially or ethnically diverse groups. Gerontologist 2005;45:634-41.

13. Johnstone MJ, Kanitsaki O. Ethics and advance care planning in a culturally diverse society. J Transcult Nurs 2009;20: 405-16.

14. Searight HR, Gafford J. Cultural diversity at the end of life: issues and guidelines for family physicians. Am Fam Physician 2005;71:515-22. PubMed PMID: 15712625.

15. Con A. Cross-Cultural Considerations in Promoting Advance Care Planning in Canada. http://www.bccancer.bc.ca/ research-programs-site/Documents/COLOUR030408_Con.pdf Canada. 2007.

16. Sinclair C, Smith J, Toussaint $Y$, et al. Discussing dying in the diaspora: attitudes towards advance care planning among first generation Dutch and Italian migrants in rural Australia. Soc Sci Med 2014;101:86-93.

17. Wallis K, Detering K, Whiteside K, et al. The effectiveness of employing exclusive advance care planning (ACP) clinicians. BMJ Support Palliat Care 2012;2:174.

18. Lorenz KA, Lynn J, Dy SM, et al. Evidence for improving palliative care at the end of life: a systematic review. Ann Intern Med. 2008;148:147-59.

19. Mullick A, Martin J, Sallnow L. An introduction to advance care planning in practice. BMJ 2013;347:f6064.

20. Scott IA, Mitchell GK, Reymond EJ, et al. Difficult but necessary conversations-the case for advance care planning. Med J Aust 2013;199:662-6.

21. Pecanac KE, Repenshek MF, Tennenbaum D, et al. Respecting Choices(R) and advance directives in a diverse community. $J$ Palliat Med 2014;17:282-7.

22. Kirchhoff KT, Hammes BJ, Kehl KA, et al. Effect of a disease-specific advance care planning intervention on end-of-life care. J Am Geriatr Soc 2012;60:946-50. 